ISSN: 0213-2079

DOI: http://dx.doi.org/10.14201/shhmo201436213232

\title{
LA ESTRATEGIA DIPLOMÁTICA DE FELIPE II FRENTE A LA TERCERA ELECCIÓN LIBRE EN LA REPÚBLICA POLACO-LITUANA, 1586-1589
}

\section{Diplomatic Strategy of Philip II towards the Third Free Election in Polish-Lithuanian Commonwealth, 1586-1589}

\author{
Matylda URJASZ-RACZKO \\ Universidad de Varsovia \\ Correo-e: urjaszm@gmail.com
}

RESUMEN: El periodo de las primeras elecciones libres en la República polaco-lituana (1573-1589) fue un tiempo especial, tanto por los cambios de régimen dentro el país como por la intensificación de los contactos internacionales. Son conocidas las misiones políticas españolas en la República y las actuaciones de los diplomáticos españoles en la corte imperial con el propósito de imponer a un Habsburgo en el trono de la República. Sin embargo el análisis de la documentación diplomática española muestra que la corte imperial no fue el único lugar, como hasta ahora se había pensado, donde la diplomacia española realizó actividades con respecto al llamado «negocio de Polonia». La diplomacia de Felipe II carecía de herramientas de actuación en la República, por eso operaba donde tenían medios, tanto a través de su embajada en el imperio como en Roma. Todo ello muestra la necesidad de investigar las relaciones entre la República y Monarquía Hispánica dentro de una perspectiva internacional, en vez de solo la bilateral.

Palabras clave: Diplomacia; Polonia; República polaco-lituana; Mancomunidad de Polonia-Lituania; República de las Dos Naciones; Enrique de Guzmán y Ribera; II conde de Olivares; Juan III Vasa; Juan Zamoyski; dominium maris baltici; batalla de Byczyna. 
ABSTRACT: The time of first free elections in the Polish-Lithuanian Commonwealth (1573-1589) was crucial because of internal political changes and intensification of international relations. Spanish diplomatic missions in Wien due to appoint a Habsburg candidate on a Commonwealth throne are known. However the analysis of the diplomatic documentations shows that imperial court was not the only place where Spanish diplomacy was struggling to achieve its aim. The diplomacy of Philip II was deprived of any tools of diplomatic actions in so called polish business, therefore they tried to have an effect wherever they could, in Wien as well as in Rome. This investigation indicate the necessity of seeing Polish-Spanish relations in the international, instead of bilateral context.

Key words: diplomacy; Poland; Polish-Lithuanian Republic; PolishLithuanian Commonwealth; Enrique de Guzmán y Ribera; II conde de Olivares; Juan III Vasa; Juan Zamoyski; dominium maris baltici; Battle of Byczyna.

El periodo de las primeras elecciones libres (1573-1589) en la República polaco-lituana fue muy significativo para sus contactos internacionales. En dicha época aumentó el interés del resto de Europa por este estado. No era tanto por la curiosidad que producían los cambios administrativos en el régimen del país, como cuanto por la posibilidad de lograr el trono de una monarquía tan grande $\left(1.036 .000 \mathrm{~km}^{2}\right)$ y tan potente como la de la República. Se presentaba una ocasión pacífica y económica de aumentar las posesiones territoriales, ganar las costas del Báltico, obtener acceso al grano y, en el caso de la Casa de Austria, fortalecer su posición geopolítica en el este de Europa y liquidar la amenaza turca. Por estas razones muchos países intentaron obtener un conocimiento sobre el estado polacolituano con el objetivo de poder actuar más eficazmente en él.

Las diferencias entre la República y los países del resto de Europa provocaron muchas dificultades para los diplomáticos extranjeros que asistieron a las elecciones libres en Varsovia. A finales del siglo xvi los países del oeste y este experimentaron cambios dentro de la organización de los estados. Las monarquías se encaminaban hacia el absolutismo, la República al contrario. A partir del año 1386 (la unión de Krewa) la Corona polaca y el Gran Ducado de Lituania estaban unidas solamente por la figura del rey de la dinastía lituana. Los Jagellones heredaban el trono en Lituania, pero en la Corona no. Aunque el trono era electivo, la aristocracia, queriendo continuar su expansión hacia el este, siempre elegía un monarca Jagellón. En el año 1569 la nobleza y el último rey de la dinastía de los Jagellón, Segismundo II Augusto estrecharon los lazos entre los dos países, mediante 
FRENTE A LA TERCERA ELECCIÓN LIBRE EN LA REPÚBLICA POLACO-LITUANA, 1586-1589

otra alianza (Unión de Lublin). El Gran Ducado de Lituania aceptó las mismas soluciones estatales que la Corona, la nobleza obtuvo privilegios de sus compatriotas de la Corona, pues a pesar de existir un rey, compartían la dieta general y la política exterior (administración, hacienda, ejercito y jurisdicción mantuvieron independientes). Tal vez el cambio que tuvo más repercusión en los contactos internacionales fue el de la posición de la aristocracia, tanto en la Corona como en Lituania. A la muerte del último Jagellón la nobleza ya había obtenido una preeminencia sobre el gobierno en el país. El año 1572 se aprovechó para dar un golpe final. La nobleza lituana aceptó la regla polaca de la elección del rey. El siguiente año legalizaron el derecho de que el poder del país pertenecía a los tres estados participantes en la dieta polaco-lituana: el rey, la magnateria (senado) y la nobleza (sejm). A partir del 1573, las elecciones sobre la persona del rey se convirtieron en verdaderamente libres. Al contrario del sistema de representación en los Países Bajos, la República de Venecia o el Imperio austriaco, en la República el derecho a votar lo tenía la nobleza del país entero (los que podían ir a Varsovia). Durante las primeras elecciones libres surgió la costumbre de elegir un candidato de la dinastía extranjera. Así querían asegurarse unas mejores condiciones en los compromisos (pacta conventa) que cada nuevo monarca juraba a sus nuevos súbditos. Además el futuro rey tenía que prestar juramento de los principios fundamentales de gobierno del país (artykuty benrykowskie). Las principales condiciones fueron que el rey podría ser elegido únicamente por libre elección, tenía que garantizar libertad religiosa (Confederación de Varsovia), estaba obligado a convocar la Dieta cada 2 años, cualquier leva de hombres o de impuestos debía ser autorizada por dicha asamblea, entre los componentes de la Dieta se nombraría a 16 senadores para que estuvieran al lado del rey y le supervisaran. Además la nobleza se reservaba el derecho de no obedecer al monarca si este incumplía las leyes de la República ${ }^{1}$. Esta fuerte posición de la nobleza y la horizontal división de poderes, en vez del orden jerárquico que existía en el oeste, representaba el mayor obstáculo para los diplomáticos españoles. A pesar de todo Felipe II decidió participar en la lucha por el trono polaco-lituano, como sus grandes rivales de Francia, el Imperio turco y otros países como Suecia, o el Ducado de Moscovia.

Los métodos aplicados por el monarca hispano y el juego diplomático internacional con referencia al llamado «negocio de Polonia», no son bien conocidos. La mayoría de los trabajos dedicados al tema presentan una perspectiva general en el largo tiempo ${ }^{2}$. Los contactos polaco-hispánicos durante la época de las tres

1. Kaczmarski, Z. y Leśnodorski, B.: Historia państwa i prawa Polski. T. II, Varsovia 1971, pp. 110-117; 176-190.

2. PrZeźDziecki, R.: «Los embajadores de España en Polonia. Desde la edad media al siglo XVII», Boletín de la Real Academia de la Historia, CXXI, 1947, pp. 397-441, además vol. CXXII, 1947 y CXXIII, 1948, pp. 295-17; AXER, J. y FonTÁN, A. (eds.): Españoles y polacos en la corte de Carlos 
primeras elecciones libres no han sido objeto de ningún estudio, salvo un par de artículos ${ }^{3}$. Hay que subrayar varios trabajos de Ryszard Skowron, aunque la mayoría se refieren al siglo xviI, como singulares artículos de Ludwik Boratyński o Maria Bogucka. Existen evidencias sobre los planes de establecer contactos económicos para importar trigo polaco a la Península Ibérica y así privar a los Países Bajos que intermediaban en este comercio de dicha fuente de riqueza. Sin embargo, hasta el momento no se conocen detalles de este proyecto; baste decir aquí que no provocó ninguna acción diplomática. Tampoco el intento de crear una Santa Liga, sobre todo durante los años 1584 y 1586, integrada entre otras potencias por España y la República, condujo a colaboración alguna entre España y Polonia. En los últimos años, a base de investigaciones sobre la Nunciatura Apostólica en Polonia, surgió el interés por la persona de Annibale di Capua, Nuncio durante el periodo de la tercera elección libre en Polonia, el cual apoyaba el interés de Felipe II $^{4}$.

Los que se ocuparon del tema han venido optando por la perspectiva bilateral, centrando su interés en las relaciones directas entre ambos países, omitiendo el aspecto internacional de ambas relaciones. Por lo que hasta ahora se ha escrito parece que las acciones hispanas se habrían limitado al apoyo a la diplomacia vienesa, y que la responsable de este asunto era la embajada española ante la corte imperial. Esta convicción se justifica por varias razones. Lo muestran perfectamente

V. Cartas del embajador Juan Dantisco. Madrid, 1994; Ruiz MarTín F.: Carlos V y la confederación polaco-lituana. Madrid, 1954; SKOwron, R.: Dyplomaci polscy w Hiszpanii w XVI $i$ XVII wieku. Cracovia 1997; SKOwRON, R.: «Polonia en las relaciones de los diplomáticos españoles de la segunda mitad del siglo XVI», Europa del Centro y del Este y del Mundo Hispanico. Simposio Internacional de Hispanistas, Blanco Picado, A. I. y Eminowicz, T. (eds.), Cracovia 1996, pp. 29-37; Góralski, Z.: «Las relaciones históricas entre España y Polonia», Trocadero, 1, 1989, pp. 37-50.

3. SKoworn, R.: Olivares, los Vasa y el Baltico. Polonia en la política internacional de España en los años 1621-1632. Varsovia, 2008; BogUCKA, M.: «Misja Franciszka Mendozy i jego opinie o Polsce», Odrodzenie i Reformacja, XIX, 1974, pp. 173-185.

4. Ruiz MARTín, F.: «La etapa marítima de las guerras de religión. Bloqueos y contrabloqueos», Estudios de Historia Moderna, III, 1953, pp. 183-214; RuIz MARTín, F: «El pan de los países balticos durante las guerras de religión. Andanzas y gestiones del historiador Pedro Cornejo», Hispania, 84, 1961, pp. 549-579; SzELĄGOWSKI, A.: Walka o Battyk 1544-1621. LVIV. 1921; BORATYŃSKI, L.: «Stefan Batory i Plan Ligi przeciw Turkom (1576-1585)», Rozprawy AU wydziat bistoryczno-filozoficzny, 44, 1903, pp. 197-347; BORATYŃsKi, L.: «Esteban Batory, la Hansa y la sublevación de los Paises Bajos», Boletín de la Real Academia de la Historia, 127, 1954, pp. 451-500; RIvero, M.: «Philip II, John III and the Sforza legacy: Patrimony and Religion in the relationships between Sweden and Spain (1573-1584)», Spain E Sweden in the Baroque Era (1600 - 1660). International Congress Records, Martínez Ruiz, E. y Pazzis Pi Corrales, M. (eds.), Madrid 2000, pp. 265-277; SKowron, R.: «Nuncjusz i ambasador. Korespondencja Annibala z Capui z Guillénem de San Clemente (15861591)», Od Kijowa de Rzymu. Z dziejów stosunków Rzeczpospolitej ze Stolicq Apostolskq i Ukrainq. Drozdowski, M. R., WalcZaK, W., Winszowata-WalcZak, K. (eds.), Białystok 2012, pp. 453-467; Bogucka, M.: «Handel Gdańska z Półwyspem iberyjskim w I połowie XVII wieku», Przeglad Historyczny, LX, 1969, pp. 1-23. 
FRENTE A LA TERCERA ELECCIÓN LIBRE EN LA REPÚBLICA POLACO-LITUANA, 1586-1589

las fuentes conocidas hasta ahora y editadas por el padre Walerian Meysztowicz en Elementa ad Fontium Editones (tomos VIII, XI, XII, XV, XVI, XIX y XXI), una pequeña serie de cartas intercambiadas entre príncipes del Imperio austriaco con Felipe II y sus diplomáticos, referentes a los años 1572-1574 y la correspondencia del embajador español en la corte imperial editada por el marqués de Ayerbe, conde de San Clemente ${ }^{5}$. En el primer y segundo casos, los documentos proceden del Archivo General de Simancas, sección Estado Alemania ${ }^{6}$. En el tercero, los documentos provienen del archivo privado de la familia San Clemente y son sobre todo cartas de la Emperatriz María y del archiduque Ernesto, referentes a la tercera elección en el estado polaco-lituano. Aunque en esta correspondencia diplomática hay huellas de contactos con otras representaciones diplomáticas hispanas, la embajada española en la corte imperial parecía la única a través de la cual la diplomacia española obtenía informes sobre Polonia, y desde donde ambas ramas de los Habsburgo actuaban.

Otra razón fue que los contactos con la República no tenían para la Monarquía de Felipe II el carácter crucial como los existentes con Francia o Inglaterra. La República y la Monarquía Hispánica tampoco mantuvieron contactos o negocios directos antes del año 1573. Por un lado, Felipe II nunca propuso un candidato propio, pero durante cada elección $(1573,1575,1587)$ apoyó a los pretendientes de la rama imperial de los Habsburgo, sobre todo al archiduque Ernesto, de quien estaba seguro por su devoción a la causa hispana, contrario a otros archiduques y al propio emperador ${ }^{7}$. Por otro lado, nunca envió a un embajador con el objetivo de realizar una misión concreta en la República polaco-lituana. Los dos diplomáticos (Pedro Fajardo y Guillén de San Clemente) que fueron a Varsovia durante la primera (1573) y la tercera elección (1587) lo hicieron mientras desempeñaban sus misiones en la corte imperial, y el viaje al país vecino les surgió como algo adicional e imprevisto. Además, en la República no se permitía ninguna embajada extranjera permanente; los diplomáticos podían visitar el país solamente durante cortos periodos de tiempo,

5. Elementa ad Fontium Editiones [en adelante EFE] es una serie de 76 tomos editada entre los años 1960-1992 en el Instituto Polaco de Historia en Roma liderado por el padre Walerian Meysztowicz. Es una edición de fuentes en las que se trataba de Polonia y que estaban dispersas entre varios archivos europeos, inaccesibles en aquellos años para los historiadores polacos; Colección de Documentos Ineditos para la Historia de España, t. 110 y 111, Madrid 1895; Correspondencia inédita de Don Guillén de San Clemente. Embajador en Alemania de los Reyes Don Felipe II y III sobre la intervención de España en los Sucesos de Polonia y Hungría 1581-1608, publicada por el marqués de Ayerbe, conde de San Clemente, Zaragoza 1892.

6. A partir del año 1569 Polonia y Lituania estuvieron unidas realmente a través de la llamada Unión de Lublin. Ambos componían un estado llamado República polaco-lituana; sin embargo, en las fuentes españoles de la época no aparece otro nombre que «Polonia». Igual situación encontramos en el material procedente de cualquier embajada y en todos los agentes españoles.

7. Chudoba, B.: España y el Imperio (1519-1643). Madrid 1963, pp. 176-190 y 258-263. 
y siempre acompañados por alguna persona asignada por el Senado. Por tanto la corte imperial era el sitio más próximo a Varsovia donde un diplomático español podía permanecer y actuar, porque hasta allí llegaba la red clientelar madrileña ${ }^{8}$.

Después de la muerte de Segismundo II Augusto, la nobleza decidió convertir el estado en una monarquía electiva. Diversos pretendientes se disputaron el trono vacante, apoyados por varias facciones nacionales y extranjeras. En 1573 el trono lo obtuvo el candidato francés Enrique de Valois, aunque entre los pretendientes figuraban Juan III de Suecia, Albrecht Hohenzollern, príncipe de Prusia, Iván IV el Terrible, príncipe de Moscovia y el archiduque Ernesto (hijo del emperador Maximiliano II y de la emperatriz María, hermana de Felipe II). Al candidato Habsburgo lo representaron ante la Dieta polaca los embajadores imperiales Vratislao de Pernestán, Guillermo de Rosenberg y el embajador español Pedro Fajardo9. Desde el punto de vista de Madrid fue un desastre, se produjo un total cambio geopolítico, porque los Valois lograron romper el círculo de los territorios de los Habsburgo que les rodeaba y ganaron frontera directa con los turcos, lo que excluía una posible formación de la Santa Liga, uno de los objetivos claves de la política exterior de Felipe II. Sin embargo el transcurso de los acontecimientos se mostró favorable para los intereses de Madrid: al recibir la noticia de la muerte de Carlos IX, rey de Francia, Enrique de Valois huyó hacia París abandonando el trono polaco. Con el fin de elegir un nuevo rey, se organizó la segunda elección. En 1575 la nobleza polaco-lituana tenía que elegir entre el emperador Maximiliano II y Esteban Báthory, príncipe de Transilvania, recomendado por el sultán Murad III, quien garantizaba la paz por parte de los otomanos. En general, todas las elecciones fueron conflictivas y tensas, en mayor o menor grado; sin embargo, durante el proceso de la tercera los conflictos se extremaron y se desataron las hostilidades entre las facciones enfrentadas. Después de la muerte del rey Esteban Báthory (el 9 de diciembre 1586 en Grodno), hubo que elegir a su sucesor como rey de la monarquía polaco-lituana. Varios pretendientes se disputaron al trono vacante.

8. Koller, A.: «El facción española y los nuncios en la corte de Maximiliano II y de Rodolfo II. María de Austria y la confesionalización católica del Imperio», La dinastía de los Austria: las relaciones entre la Monarquía Católica y el Imperio, MARTíneZ Millán, J. y GonZÁlez Cuerva, R., t. I, Madrid 2011, pp. 109-124; PAVEL, M.: «Las damas de la emperatriz María y su papel en el sistema clientelar de los Reyes españoles. El caso de María Manrique de Lara y sus hijas», Las relaciones discretas entre las Monarquias Hispana y Portuguesa: las casas de las reinas (siglos XV-XIX), MARTÍNEZ Millán, J., t. II, Madrid, 2008, pp. 1003-1013; EdelmaYer, F.: «La red clientelar de Felipe II en el Sacro Imperio Romano Germánico", Torre de los Lujanes, 33, 1997, Madrid, pp. 129-142.

9. Rodríguez Pérez, R. A.: «Servir al rey, servir a la casa. La embajada extraordinaria del III marqués de los Vélez en el Imperio y Polonia (1572-1575)», La dinastía de los Austria: las relaciones entre la Monarquía Católica y el Imperio. Martínez Millán, J. y González Cuerva, R. (eds.), t. I, Madrid, 2011, pp. 439-478; WIERZBOwsKI, T.: «Zabiegi cesarza Maksymiliana II o koronę polską 1565-1576», Ateneum, III, 1879, pp. 407-446 y IV, 1879, pp. 52-89; PÁNEK, J.: Wilhelm z Rożemberka. Polityk pojednania. Opole 2007, pp. 207-212. 
FRENTE A LA TERCERA ELECCIÓN LIBRE EN LA REPÚBLICA POLACO-LITUANA, 1586-1589

Entre ellos destacaban dos: el archiduque Maximiliano, designado Gran Maestre de la Orden Teutónica y administrador de Prusia, hijo del emperador Maximiliano II Habsburgo y de María de Austria, y su oponente el príncipe de Suecia Segismundo Vasa, hijo del Juan III de Suecia y de Catalina de Jagellón (hija del rey polaco-lituano Segismundo I el Viejo, 1467-1548). El día 19 de agosto la mayoría de la nobleza eligió a Segismundo Vasa, el príncipe sueco. Pero tres días después (22 de agosto), la facción minoritaria, fiel a los Habsburgo, a quienes veían como garantes de su posición en el estado, organizó una elección alternativa prefiriendo al archiduque Maximiliano como rey de la República. La validez de las elecciones se solventó en el campo de batalla. Cuando Maximiliano y los magnates que le apoyaban estaban intentando sitiar la ciudad de Cracovia, las tropas del príncipe de Suecia derrotaron en la batalla de la cercana Byczyna, el 24 de enero 1588, a las fuerzas de los Habsburgo. El archiduque Maximiliano fue hecho prisionero por el poderoso canciller Juan Zamoyski, jefe de los ejércitos del príncipe sueco, y quedó bajo arresto hasta el 10 de marzo 1589, cuando los dos bandos firmaron la paz según la cual el Habsburgo renunciaría a todas sus pretensiones sobre el trono polaco. El Emperador Rodolfo II, sus hermanos los archiduques Ernesto, Matías y su tío Fernando de Tirol reconocieron el tratado en ese mismo año; sin embargo, el archiduque Maximiliano y Felipe II no lo aceptaron hasta el año 1598.

Para la nobleza polaco-lituana, la elección del Vasa constituía la culminación de un viejo plan que aunaba el dominium Maris Baltici (dominación del Mar Báltico) y la constitución de una alianza contra Moscovia y Dinamarca. Significaba también la paz con Turquía. Por el contrario, la elección del archiduque Maximiliano representaba la liquidación del Intermarium, la zona de los países independientes o semiindependientes entre los Habsburgo, el Imperio Otomano, y los confines de Europa. El reforzamiento de la posición de los Habsburgo en estos territorios representaría para la República la obligación de elegir entre la potencia otomana y los Habsburgo. La nobleza polaco-lituana no quería repetir el caso de sus vecinos como Hungría o Moldavia y Valaquia. Tal vez otros dos factores fueron aún más importantes para la nobleza, la cual temía que un rey Habsburgo limitara sus libertades y derechos, igual que ya lo había hecho en Hungría. Asimismo, temían también ser forzados a participar en la liga antiturca auspiciada por los Habsburgo. Así que en 1587 ganó la posición más extendida entre la nobleza, que no buscaba una alianza política con el oeste, sino que centraba sus intereses (comerciales sobre todo) a lo largo del eje entre el Báltico y el Mar Negro, en el llamado Intermarium ${ }^{10}$.

10. Nowak, A.: Was the Polish-Lithuanian Commonwealth an empire? <http://src-h.slav. hokudai.ac.jp/coe21/publish/no7_ses/chapter12.pdf>. 
La experiencia de las dos elecciones anteriores demostró la existencia de una muy mala colaboración entre Madrid y la corte cesárea hacia el «negocio de Polonia». Ni el emperador Maximiliano II, ni su sucesor querían perjudicar las relaciones existentes en el territorio de Intermarium (la República, Valaquia, Transilvania, Moldavia) y no estaban dispuestos a acciones forzosas o militares. Queda por comprobar hasta qué punto el emperador jugaba con Felipe II en esta materia, manteniendo y controlando a la vez la involucración de Madrid en la política del este como una amenaza contra Turquía y sus aliados. La discordia entre las dos ramas de los Habsburgo aumentó por los desacuerdos en la política exterior con referencia a los Países Bajos y la expansión española en Italia. Incluso emperadores como Maximiliano II y Rodolfo II no simpatizaban con Felipe II en las cuestiones religiosas. A los embajadores españoles les resultó muy difícil imponer su estrategia del «negocio de Polonia» a la diplomacia imperial, a los que además veían como poco profesionales, acusándoles de falta de decisión, de pereza y de ocultar ciertas informaciones. La experiencia de la primera y secunda elección dejó claro, ante los ojos de la diplomacia española, que la red clientelar del Imperio en la República no estaba tan desarrollada, ni era tan fiable, como les aseguraban los diplomáticos imperiales ${ }^{11}$.

Por ello, a partir de la segunda elección la diplomacia hispana empezó a buscar otras posibilidades para acercarse al mundo polaco. En el periodo entre la segunda y tercera elección la mayor fuente de informaciones desde la República se recibió desde las embajadas españolas en la corte imperial y en Venecia, y sistemáticamente creció el papel de la embajada en Roma. Durante la tercera elección las cartas dedicadas al tema polaco llegaban a Madrid no solamente desde la corte imperial, sino también desde Venecia y Roma. Además la embajada romana llegó a ser no solamente el centro de obtención de informaciones sino sobre todo el de actuación hacia el «negocio de Polonia» ${ }^{12}$.

11. JanaČeK, J.: Rudolf II. a jeho doba. Praga, 1987, pp. 30-45; MAReK, P.: «La diplomacia española y la papal en la corte imperial de Fernando II», Studia Historica. Historia Moderna, 30, 2008, pp. 109-143; Rodríguez-Salgado, M. J.: «I loved him as a father loves a son ... Europe damn me then, but I deserve his thanks». Philip II's relations with Rudolf II», La dinastia de los Austria. Las relaciones entre la monarquía Católica y el imperio, MARTínez Millán, J. y GONZÁlez Cuerva, R. (eds.), Madrid, 2011, pp. 335-389.

12. La autora del artículo realizó la busqueda referente al «negocio de Polonia» tanto en la sección Estado y Consejo de Estado en el Archivo General de Simancas, como en los archivos de Instituto Valencia de Don Juan, Archivo y Biblioteca de Francisco de Zabalburu y el mencionado Archivo del Ministerio de Asuntos Exteriores, dedicados a los años 1572-1592. Los resultados muestran que durante la tercera elección libre el 15\% de las cartas procedentes de la embajada en Roma contenían informaciones no solamente sobre Polonia, sino también escritas desde Polonia. Representó un cambio significativo en comparación con las elecciones posteriores. La cuestión está desarrollada en la tesis doctoral. 
Las fuentes referentes a la tercera elección se encuentran en el ya mencionado Archivo General de Simancas así como en el Archivo de Ministerio de Asuntos Exteriores, en la sección Santa Sede (legajos 2 y 17), bajo el título Reino de Polonia. Algunos documentos pueden permanecer en la nunciatura en España en Roma ${ }^{13}$. Sin embargo dicho conjunto abarca la mayoría de los documentos y es suficiente para ampliar la imagen de las acciones de los Habsburgo (tanto los imperiales como los de Madrid) en la República, tanto como para mostrar la forma de comportamiento de la diplomacia hispánica en territorios lejanos en los que carecían de cualquier punto de apoyo ${ }^{14}$.

Después de la muerte del rey Esteban Báthory, y con relación a los acontecimientos de la República, para Felipe II y su embajador en Roma, Enrique de Guzmán y Ribera, II conde de Olivares, la conveniencia de actuar a través de Roma resultó evidente ${ }^{15}$. Roma tenía una larga tradición de mantener a su enviado en la República durante largos periodos de tiempo ${ }^{16}$. Gracias a esto, los Nuncios lograron conocer bien la realidad polaco-lituana.

$\mathrm{Al}$ contrario que en la corte imperial, en Roma la influencia de los españoles era enorme. Les era mucho más fácil actuar y lograr sus objetivos políticos que en cualquier otro lugar ${ }^{17}$. Así, la Santa Sede representaba una excelente alternativa. Tenía sus propias redes de contactos y sus sistemas de información, y algo más, la autoridad del Papa. El Nuncio era el único diplomático extranjero con derecho a permanecer en la República por periodos más largos. Ello significaba que podía libremente viajar, establecer contactos personales y, sobre todo, influir en los eclesiásticos de todo el país. Era un elemento crucial en un estado donde los Habsburgo del imperio y los de Madrid tenían una escasa red clientelar.

13. Indices de la correspondencia entre la Nunciatura en España y la Santa Sede, durante el reinado de Felipe II, ed. Garmendía, J. O. y LaRRAmendi, M. L., t. I, II, Madrid 1948-1949.

14. Sobre los métodos aplicados por la diplomacia española en Roma vid. Giordano, S.: Istruzioni di Filippo III ai suoi ambasciatori a Roma 1598-1621. Roma, 2006.

15. Carta de Felipe II al conde de Olivares, 22 de febrero 1587, Archivo del Ministerio de Asuntos Exteriores [en adelante AMAE], Madrid, Santa Sede 17, fol. 100: «Sin las cartas que en otra se os avisa que se han recibido otras han llegado tenbien las de 30 y postrero de diziembre y no de 8 de henero por esta postrera he entendido la muerte del Rey de Polonia y el oficio que vos pensavades hazer con Su Sd. Me parece tan acertado que ninguna orden pudi.a danseos de aca que mas lo fuesse y assi os lo agradezco y encargo que lo vais continuando que la misma conformidad y llegando a señalar q seprocure que entre alli el emp.or mi sobrino o uno de sus her.nos que creo es lo que el mas querra pero hasta ver carta suya y avernos comunicado es bien q se diga assi y cae muy en razon que por respecto del bien pu.co y de la causa catolica aya de holgar Su Sd. de favorecer nra casa vos se lo pedi el de mi parte valiendoos delas razones q mas le puedan inclinar a ordenar a $\mathrm{Su}$ legado que ayude aesta pretension y de aca se os yra avisando ...».

16. WóCIK, Z. (ed.): Polska stużba dyplomatyczna w XVI-XVII wieku. Varsovia, 1966, p. 175.

17. Dandelet, T. J.: La Roma Española (1500-1700). Barcelona, 2002. 
La estrategia de la diplomacia española tenía dos metas: la construcción de un fuerte y estable bloque prohabsburgo en el ámbito europeo, con la participación clave del Papa, y el impulso de la candidatura de un Habsburgo ${ }^{18}$. El cerebro de todas las acciones era el conde de Olivares, embajador en Roma. Así su embajada se convirtió en el centro de actuación y coordinación de las informaciones referentes al llamado «negocio de Polonia».

En la corte cesárea era muy difícil actuar y obtener informaciones. Los culpables de la complicada situación eran la rivalidad existente entre los archiduques y el lento proceso decisorio por parte del emperador Rodolfo II: «la tibieza con que va el emperador, y los errores que en el modo de negociar se hazen, y la competencia de los dos hermanos, que es de temer que han de gastar el buen negocio que con el favor y autoridad de V. Mg. se les ha acomodado» ${ }^{19}$. En efecto, en la fase de preparativos para la elección, los archiduques rivalizaban en la corte imperial: Ernesto, Maximiliano, Matías y su tío Fernando de Tirol. El emperador no quiso nombrar a ninguno de ellos como candidato de la Casa de Austria, ni tampoco el $\mathrm{Papa}^{20}$. Debían luchar entre sí.

El favorecer la elección del archiduque Ernesto era importante para Felipe II pero no fundamental. El rey de la Monarquía Hispánica quería en el trono al archiduque Ernesto, su sobrino favorito, educado en la corte de Madrid, de quien se podía fiar. Le dio su apoyo en las primeras dos elecciones en la República, en los años 1573 y 1575. Pero en 1587 el archiduque Maximiliano decidió tener más iniciativa tomando una actitud más activa, y empezó por asegurarse el apoyo de su hermano el archiduque Matías y de la Orden Teutónica. Ni la facción española en la corte imperial ni la diplomacia hispánica le impidieron hacerlo ${ }^{21}$. Tampoco lo hizo su hermano, el archiduque Ernesto. Al final, a la elección se propusieron dos candidatos Habsburgo: los archiduques Ernesto y Maximiliano. Después de la derrota del archiduque Ernesto, Felipe II no disminuyó su compromiso con el «negocio de Polonia». Al contrario, con la misma fuerza luchó, a través de su diplomacia, por la elección, y después por la liberación del archiduque Maximiliano, y por la paz justa, honrosa (según Felipe II), entre la República y la Casa de Austria. La rivalidad entre los hermanos fue perfectamente aprovechada por

18. Felipe II al conde de Olivares, Madrid 11 de febrero 1587. Archivo General de Simancas [en adelante AGS], Estado, leg. 949, fol. 123.

19. Conde de Olivares a Felipe II 1 de mayo 1587, de Roma AGS, Estado, leg. 948, fol. 168; Guillén de San Clemente escribía al conde de Olivares quejándose de que «en el negocio de Polonia no me an hablado hasta ahora palabra...», AMAE, Santa Sede, leg. 17, fol. 87.

20. Rodolfo II al Presbítero Cardenal Lodovico Madruzzo, Praga, 28 de enero 1587. AGS, Estado, leg. 948, fol. 100; Conde de Olivares a Guillén de San Clemente, Roma, 14 de febrero 1587. AGS, Estado, leg. 948, fol. 83.

21. AMAE, Santa Sede, leg. 17, fol. 88. 
las facciones de la República, jugando con ella y dando su apoyo a uno o al otro de los Habsburgo.

La elección en la República polaco-lituana tuvo también un papel importante en el juego geopolítico interno de Italia. Así, tenemos el caso de Vespasiano Gonzaga, duque de Saboya, yerno del Rey Católico, que también aspiraba a la sucesión al trono polaco-lituano. Le interesaba no tanto el trono sino el apoyo de Felipe II para mejorar su posición en Italia y detener las constantes disputas con el duque de Florencia. Al final, su candidatura no llegó a proponerse, pero durante los primeros meses después de la muerte del rey Esteban Báthory, fue una cuestión bastante discutida en Roma, sobre todo gracias a los cardenales Mondori y Rovere, quienes le dieron su apoyo ${ }^{22}$. En la segunda fase del «negocio de Polonia», después del encarcelamiento del archiduque Maximiliano (batalla de Byczyna), Felipe II decidió utilizar en su propio provecho las ambiciones del duque. El «Rey Prudente» consideraba crucial influir en la decisión y actuación de la diplomacia imperial para adelantar la liberación del archiduque y mantener la autoridad de la Casa de Austria en la arena internacional. Aprovechó la decisión de Rodolfo II de convocar una junta para debatir sobre el asunto del archiduque Maximiliano. Para ello decidió enviar a Vespasiano Gonzaga, duque de Saboya, junto con el napolitano doctor Josepe Riva, a la junta y resto de actuaciones que pudieran tener lugar ${ }^{23}$. Como siempre, la resolución de los problemas en el imperio se prolongó, así el 3 de junio de 1588 Vespasiano Gonzaga informaba de que posponía su salida de Saboya porque la junta, prevista para finales del mes de abril, aún no había tenido lugar ${ }^{24}$.

El papa Sixto V no era partidario de Felipe II y no apoyaba su política, sin embargo tenían muchos objetivos comunes, como la lucha contra la herejía, o la reforma de la Iglesia, pero no estaban de acuerdo en otros varios aspectos de la política internacional. En este tiempo, el mayor desacuerdo y las constantes discusiones del Papa con el conde de Olivares fueron provocados por los asuntos de Inglaterra y Francia ${ }^{25}$. Con el avance de la Reforma, y ante la situación geopolítica,

22. Baron Sfondrato al conde de Olivares, Turín, 30 de enero 1587. AMAE, Santa Sede, leg. 17, fol. 101; Paolo Sfondarto, mayordomo de la hija de Felipe II y embajador de España en Turín, era el responsable de tener constantemente informada a Madrid tanto de los asuntos personales y domésticos de la corte turinesa como de las actividades políticas del duque de Saboya.

23. Felipe II a Vespasiano Gonzaga, duque de Saboya, El Pardo, 6 de abril 1588, AMAE, Santa Sede, leg. 17, fol. 44; Vespasiano Gonzaga, duque de Saboya al conde de Olivares, Saboya, 23 de mayo 1588, AMAE, Santa Sede leg. 17, fol. 113.

24. Vespasiano Gonzaga, duque de Saboya al conde de Olivares, Saboya, 3 de junio 1588, AMAE, Santa Sede, leg. 17, fol. 112.

25. Hinojosa, R.: Los despachos de la diplomacia pontificia en España. t. I, Madrid 1896, pp. 317-325. Levin, M. J.: Agents of Empire. Spanish Ambassadors in Sixteenth-Century Italy. EUU, 2005, p. 116; García Hernán, E.: «La Curia Romana, Felipe II y Sixto V», Hispania Sacra, vol. XLVI, 1994, pp. 640-649. 
la Santa Sede decidió dar su apoyo secreto a los Habsburgo. Para Roma, lo más importante era mantener estable el bloque católico en los límites de los territorios católicos de Europa, como contrapeso al Imperio Otomano. Aunque los territorios de Hungría y de Transilvania formaban parte de la frontera directa con el citado Imperio, Roma los consideraba inseguros. Transilvania era un feudo turco, que existía gracias a una ágil política de contrapesos entre el sultán y el emperador. La República era un país fuera de la monarquía de los Habsburgo, pero una gran potencia militar y territorial. Aunque la República era considerada un país dudoso religiosamente, creían que con favorables circunstancias geopolíticas se implicaría en el ataque por tierra a Turquía junto con el imperio austriaco, Moscovia y Georgia $^{26}$. El príncipe sueco, aunque católico, no garantizaba la política hacia el sureste, sino que dirigía sus intereses hacia Suecia y el Báltico. El candidato de Moscovia, Fiódor I, aseguraba que sus planes incluían el ataque contra el Imperio Otomano, pero no tenía el apoyo de la clase alta de la República, y además le consideraban un hereje. En estas circunstancias, solo el Habsburgo garantizaba a Roma el avance de la Contrarreforma en esta parte fronteriza de Europa y una postura coincidente con la del Papado frente al Imperio Otomano ${ }^{27}$. El otro asunto que importaba a la Santa Sede fueron las pretensiones del denario de San Pedro. El rey de la República en vez de devolver estas sumas a Roma empezó a destinarlas a la defensa de las fronteras del Sur, contra los ataques otomanos a los territorios polaco-lituanos, pero este asunto quedaba para discusión después de la elección ${ }^{28}$.

A pesar de la favorable actitud de la Santa Sede hacia los intereses de la Casa de Austria en esta materia, Roma tenía su política, independiente de la de los Habsburgo, y durante meses el apoyo no fue seguro, además de que no estaban bien definidas las condiciones para dicho apoyo. Al final, mucho dependía de la política de nombramientos y de cumplimento de las promesas del Papa. Desgraciadamente para la facción española, el responsable del «negocio de Polonia» en Roma era el cardenal Girolamo Rusticucci, secretario de estado de la Sede del Pontífice, desfavorable a los Habsburgo ${ }^{29}$. La facción habsbúrgica tenía que apoyarse en

26. Guillén de San Clemente al conde de Olivares, Febrero 1588, AMAE, Santa Sede, leg. 17, fol. 2 .

27. Probablemente Ippolito Aldobrandini, «Discurso por donde se muestra q [..] serviria de Casa Appostolica importa q sea electo Rey de Polonia alguno del soberanos de Casa de Austria y q ninguno otro deseo pretensiesee aproposito sus fines», AMAE, Santa Sede, leg. 17, fol. 66; NANKE, CZ.: Z dziejów polityki Kuryi Rzymskiej wobec Polski (1587-1589). Lviv, 1921, pp. 17-18.

28. Conde de Olivares a Felipe II, Roma, 8 de mayo 1588, AGS, Estado, leg. 950, fol. 87.

29. Conde de Olivares a Guillén de San Clemente, Roma, 30 de abril 1588, AGS, Estado, leg. 950, fol. 40 (2); HiNOJOSA, op. cit., p. 333: constata que el cardenal Rusticucci salvo su puesto, estaba privado de su poder durante el pontificado del Papa Sixto V, de asuntos exteriores realmente se ocupaba Dezio Azzolini, Obispo de Cervia, secretario íntimo del Papa y a partir de octubre de 1587 el cardenal Alessandro Montalto. 
otros personajes como el viejo cardenal Lodovico Madruzzo, príncipe-obispo de Trento, quien estaba en funciones de emisario imperial (1532-1600). Junto con el conde de Olivares hicieron lo posible para que el Papa mandara a la República un legado fiel a la Monarquía Hispánica. Al principio veían en el cargo a Honorato Gaetani, conde de Carpi, (enviado a Polonia años más tarde, en 1596-1597), pero en ese momento no lograron imponer su candidatura ${ }^{30}$. En el nombre del papa Sixto $V$ actuaba el Nuncio, nombrado un mes antes de la muerte del rey Esteban Báthory, Annibale di Capua, arzobispo de Nápoles. Sixto V apoyaba la política de Esteban Báthory hacia Moscovia y Turquía, y con este propósito, a finales de 1586 mandó a la República al Nuncio y a Antonio Possevino, un gran conocedor de asuntos de la Europa del este. Su misión coincidió con la muerte del Rey, pero el Papa ordenó al Nuncio proseguir su viaje. En los primeros meses, el Pontífice dio solo una instrucción a su embajador: apoyar la elección de cualquier candidato que fuera católico ${ }^{31}$. Su apoyo al Habsburgo, instrucción transmitida al arzobispo por el cardenal Alessandro Montalto (uno de los cardenales más fieles al Papa Sixto V y el miembro de la comisión dedicada a asunto de Polonia en Roma), llegó meses más tarde, en la instrucción secreta fechada el 30 de mayo de $1587^{32}$. Sin embargo la actitud de los eclesiásticos romanos frente la candidatura habsbúrgica no era unánime. Cuando el jesuita Possevino denegó el apoyo a cualquier candidato Habsburgo y se puso al lado del príncipe sueco, el Papa le revocó el mandato ${ }^{33}$.

Una figura clave en la estrategia del conde de Olivares lo constituía la figura del Nuncio. El arzobispo de Nápoles procedía de la familia napolitana de los condes Termoli, y ya tenía experiencia norteña desde su misión en la corte imperial en 1576, probablemente el momento en que por primera vez estableció relaciones políticas con los Habsburgo. Otro hecho importante para sus relaciones con la Casa de Austria fue su nombramiento como arzobispo de Nápoles en $1578^{34}$. Así, antes de su salida hacia el norte, el conde de Olivares logró explicarle qué significaba ser súbdito del monarca más poderoso del mundo. Del resultado de su misión dependía su promoción al cardenalato, que obtuvo después de cumplir su cometido por su fiel servicio en la República ${ }^{35}$. De modo que enseguida escribió

30. Felipe II a conde de Olivares, 22 de febrero 1587, AMAE, Santa Sede, leg. 17, fol. 100.

31. BANASZAK, M.: Z dziejów dyplomacji watykańskiej. Poselstwa obediencyjne w latach 15341605. Varsovia, vol. II, 1975, pp. 194-195.

32. NANKe, op. cit., p. 25.

33. El papa Sixto V apoyaba la politica de Esteban Báthory, entre otros medios por la politica de Antonio Possevino. Despues la muerte del monarca, el Papa se puso al lado de los Habsburgo. Al fracaso en la tercera elección, el Pontífice volvió al proyecto que Possevino había presentado con anterioridad. Más información en CACCAMO, D.: Roma, Venezia e l'Europa centro-orientale. Ricerche sulla prima età moderna. Milano 2010, pp. 53-63.

34. NANKe, op. cit., pp. 9-12.

35. Conde de Olivares a Felipe II, Roma, 16 de octubre 1587, AGS, Estado, leg. 949, fol. 100. 
a Guillén de San Clemente, a Juan de Zúñiga, y al conde de Olivares cartas en las cuales aseguraba su lealtad ${ }^{36}$. El arzobispo de Nápoles pronto se convirtió en el pilar de la política española en la República y la única fuente fiable de informaciones de estos territorios durante su estancia desde marzo de 1587 hasta abril de $1591^{37}$. Después de su salida, en septiembre de 1591, cuando estaban en marcha las negociaciones del matrimonio entre Segismundo III Vasa y Anna Habsburgo, San Clemente se quejaba a Felipe II de que desde que salió el arzobispo no se sabía nada seguro de las cosas de Polonia ${ }^{38}$.

Se desconoce hasta qué punto el Papa era consciente de las preferencias políticas del arzobispo de Nápoles. Aunque son conocidas sus diferencias con Felipe II y su embajador en Roma, el conde de Olivares ${ }^{39}$. Aquel informaba a Guillén de San Clemente y al conde de Olivares sobre las decisiones en Roma, en la corte imperial y en la República polaco-lituana. Era el responsable de actuar secretamente con la facción española y apoyarla en la República. Gracias a su función, tenía derecho a estar en la misma y podía contactar con personalidades diversas. Muchos recibieron de él costosos regalos con el objetivo de ganar sus votos ${ }^{40}$. En sus cartas informaba de sus fructíferos contactos con el canciller Juan Zamoyski, el mayor partidario del candidato sueco, o con el primado de la República, Estanislao Karnkowski, arzobispo de Gnesna. Probablemente exageraba sus méritos, pero logró su objetivo. Según Guillén de San Clemente no hubieran podido esperar mejor hombre en su puesto, y los posibles fallos que hubieran podido ocurrir habían sido por culpa de los oficiales imperiales:

El Arzobispo de Napoles procede como se puede dessear y que V.S. no se ha enganado de lo que del ha siempre dicho y confiado yo ando tan unido con el como es razon y la mayor amistad que hasta ahora hallamos es causada por culpa nuestra pues son tantos los pretensores deesta casa y tantas las platicas que por cada uno deellos se hazen que vienen a debilitar nuestra faction pues se divide en tantas partes y el venir como venimos son un Real donde tantos son forcadamente menester podria quitarnos esta corona mas que no los demas pretensores que ay para ella ${ }^{41}$.

36. Carta de Annibale di Capua a Alejandro Farnesio, Roma, 23 de Noviembre 1586, en Woś, J.: Annibale di Capua, Nunzio apostolico e arcivescovo di Napoli (1544 c.-1595). Materiali per una biografia, Roma, 1984, p.69: «...ma particolarmente per la speranza che in quelle parti potesse venirmi occasione di servire ancora alla Maesta del Re Nostro Signore et la persona do Vostra Alteza».

37. Woś, op. cit., pp. 66-67.

38. Guillén de San Clemente a Felipe II, Praga, 17 de septiembre 1591, AGS, Estado, leg. 698, fol. 199, también en EFE vol. XIX, n. ${ }^{\circ}$ 27, pp. 26-27.

39. HinojosA, op. cit., pp. 317-335.

40. Conde de Olivares a Felipe II, Roma, 22 de noviembre de 1587, AGS, Estado, leg. 949, fol. 89.

41. Guillén de San Clemente a conde de Olivares, primeros meses de 1587, AMAE, Santa Sede, leg. 2, fol. 222. 
FRENTE A LA TERCERA ELECCIÓN LIBRE EN LA REPÚBLICA POLACO-LITUANA, 1586-1589

Su apoyo a la Casa de Austria era tan visible que la nobleza polaco-lituana le trataba como un filohabsbúrgico en vez de como un enviado papal independiente. Después de la doble elección, y el encarcelamiento del archiduque Maximiliano, la diplomacia española intentó promover la imagen internacional de la ilegitimidad de la elección del príncipe sueco, focalizando sus acciones sobre todo en Roma. En juego estaban el trono de la República y el prestigio de la Casa de Austria.

La embajada en Roma resultó muy eficaz en el caso de la misión de Estanislao Reszka, conocido y apreciado eclesiástico, ex secretario del embajador polaco en Roma, enviado de Segismundo Vasa y del Senado de la República a Venecia, Ferrara y a la Sede Pontíficia ${ }^{42}$. En el caso de los dos primeros estados iba a ofrecer la disponibilidad de la República para una alianza anti Habsburgo; en Roma, su misión consistía en relatar la elección, ganar el apoyo del Papa para el nombramiento electivo del Vasa, y ofrecer la obediencia del nuevo rey. Cuando en marzo de 1588 Reszka salió de Cracovia hacia Roma, el cardenal Ludovico Madruzzo remitió al Papa Sixto V un memorial en el que le informaba de la próxima llegada de Reszka, y explicaba la ilegitimidad de la elección del archiduque Maximiliano, adelantando la versión presentada por el enviado ${ }^{43}$. La misión de Reszka fue muy fructífera para el Vasa: logró mostrar al Papa la versión verdadera de la elección, le aseguró que el reconocimiento del sueco era la única manera de mantener la paz en la República, y le indicó la perspectiva de una posible recatolización de Suecia. Con estos argumentos en la audiencia privada Sixto V reconoció la elección y accedió a las demandas de Reszka para excluir al arzobispo de Nápoles de las negociaciones en el conflicto y nombrar un nuevo legado ${ }^{44}$.

La facción española hizo todo lo posible para bloquear la nominación del nuevo legado, a fin de que el arzobispo de Nápoles permaneciera en la República como único representante del Papa. Otro objetivo era detener el reconocimiento del príncipe sueco como rey de la República por parte del Papa y su enviado a la misma ${ }^{45}$. Lograron solo que el Pontífice no cesara al arzobispo de Nápoles como Nuncio, por lo que pudo permanecer en la República junto al nuevo legado, el florentino Ippolito Aldobrandini (el futuro papa Clemente VIII), protegido del cardenal Farnese, partidario del Gran Duque de Toscana. En su misión le acompañaron muchos oficiales, pero sus colaboradores más cercanos fueron el auditor de la Rota, el boloñés Bianquetto, y el abate Tolosano de Nápoles, a quienes la

42. Wо́јсік, Z. (ed.): Historia dyplomacji polskiej. Varsovia, vol. II, 1966, pp. 25.

43. Cardenal Madruzzo a Su Santidad Sixto V, mayo 1588, AMAE, Santa Sede, leg. 17, fol. 46,

44. Conde de Olivares a Guillén de San Clemente, Roma, 30 de abril 1588, AGS, Estado, leg. 950 , fol. 40 (2).

45. Conde de Olivares a Guillén de San Clemente, Roma, 7 de mayo 1588, AGS, Estado, leg. 950 , fol. 89 . 
FRENTE A LA TERCERA ELECCIÓN LIBRE EN LA REPÚBLICA POLACO-LITUANA, 1586-1589

facción española en Roma consideraba personas fieles a Felipe $\mathrm{II}^{46}$. El objetivo de la misión del legado era el establecimiento de la paz y la liberación del archiduque Maximiliano.

Después de la elección del príncipe de Suecia y del encarcelamiento del mencionado archiduque, además de la reputación de la Casa de Austria, el problema más urgente era el posible desarrollo de la herejía en tierras polaco-lituanas, ya que el catolicismo del sueco era muy dudoso, y más aún el de su familia. Se sabía que el príncipe de Suecia, único heredero del trono de su país, quería volver a Estocolmo. La estrategia española en Roma consistía en impulsar el matrimonio del archiduque Maximiliano con la princesa sueca, para que Segismundo Vasa pudiera volver a su estado natal dejando el trono al archiduque. Tenían el apoyo de Moscú, del rey de Dinamarca, que temía cualquier reforzamiento de Suecia, y obviamente del emperador y de Felipe II. El plan parecía casi perfecto, hasta que estuvo claro que la princesa sueca era hereje. En esas circunstancias el plan debió abandonarse ${ }^{47}$. Años más tarde, en 1591, la diplomacia imperial consiguió casar a Segismundo III Vasa con Anna Habsburgo, hija del archiduque Carlos, pero este asunto no tuvo relación, que sepamos, con la diplomacia española. En 1588 estaba en juego la intervención militar, pero el papa Sixto V no dio apoyo financiero al archiduque, y pronto reconoció oficialmente a Segismundo Vasa como rey de la República polaco-lituana. En estas circunstancias, Roma esperaba la continuación del viejo plan de Antonio Possevino que consistía en la recatolización de Suecia ${ }^{48}$.

La correspondencia contiene muchas cartas intercambiadas entre el conde de Olivares, Guillén de San Clemente, y Annibale de Capua, siendo visibles los contactos con el cardenal Madruzzo, pero no hay evidencias de cooperación (solamente contactos) con los diplomáticos imperiales, también comprometidos al servicio de la Casa de Austria. Parece que la diplomacia española mantenía su canal romano casi independientemente del imperial. Además se apoyaron solamente en la persona de arzobispo de Nápoles. Finalmente, las garantías solemnes del Nuncio de sus buenos contactos con el cardenal Radziwill, el primado Estanislao Karnkowski, arzobispo de Gnesna, o con el propio canciller Juan Zamoyski, resultaron falsos. Baste decir que durante la ceremonia de coronación del archiduque Maximiliano, el cardenal Radziwill no estuvo presente. El segundo pilar de la facción prohabsbúrgica, el primado Estanislao Karnkowski, también falló; tampoco estuvo presente durante la coronación, no le nombró Rey, como hubiera sido lo esperado según la ley, y lo tuvo que hacer el obispo de Kiev, Jacobo

46. Información de la persona y condiciones del cardenal Aldobrandini y su nombramiento para legado para la pacificación de las cosas de Polonia, AGS, Estado, leg. 950, fol. 109-110.

47. Felipe II al conde de Olivares, El Pardo, 7 de abril 1588, AGS, Estado, leg. 951, fol. 112; conde de Olivares a Felipe II, Roma, 2 de mayo 1588, AGS, Estado, leg. 950, fol. 91.

48. NANKe, op. cit. pp. 34-35. 
FRENTE A LA TERCERA ELECCIÓN LIBRE EN LA REPÚBLICA POLACO-LITUANA, 1586-1589

Woroniecki. Además, Karnkowski muy pronto coronó a Segismundo Vasa, excusándose ante Alejandro Farnesio, protector de Polonia, manifestándole que lo hizo por presión de la nobleza, y contra su voluntad. Parece que la lógica de la diplomacia española era errónea. Creían que teniendo asegurados los votos de los líderes de Lituania y de la Iglesia tendrían seguros los de sus súbditos. La realidad reveló que ni toda la familia de los Radziwill se mostró conforme con la postura del cardenal, ni los eclesiásticos de la República siguieron al arzobispo de Gnesna. La nobleza guardaba su independencia, incluso los partidarios de los Habsburgo no toleraban injerencias extranjeras y no se sintieron obligados a seguir la voluntad de aquellos o de los eclesiásticos.

La embajada española en Roma jugó un gran papel en la tercera elección libre. Las fuentes muestran que los diplomáticos hispanos no subordinaron «el negocio de Polonia» a ningún otro asunto. Fue en sí mismo importante, y tratado con mucho compromiso por parte de los diplomáticos. Con seguridad se puede confirmar el gran trabajo realizado por parte del conde de Olivares y de sus colaboradores, aunque solo lograron éxitos parciales. Hay que recordar que la diplomacia española no actuaba independientemente, y por eso es difícil juzgar el nivel de su importancia, separar los objetivos del resultado o las acciones de la embajada en Roma de las de la embajada ante la corte imperial, así como las decisiones prohabsburgo del Papa que fueron resultado de la ágil política de los diplomáticos españoles. Desde el principio hicieron esfuerzos para que el Papa diera su apoyo a la Casa de Austria, y al final la respuesta positiva llegó en marzo 1587. Luego, aunque no propusieron un candidato para el puesto de legado en la República, lograron conseguir un fiel colaborador en la persona del arzobispo de Nápoles. Entre los éxitos figuró también la prolongación de su misión hasta 1591, el descrédito de la elección de Segismundo Vasa en el ámbito internacional, y por último la larga lucha por el rechazo de la versión «polaca» de la paz con la Casa de Austria como humillante para los Habsburgo. Quizá estas acciones tuvieron alguna influencia en la rápida búsqueda por parte de Segismundo Vasa del establecimiento de buenas relaciones con los Habsburgo, y su boda con Anna Habsburgo o, años más tarde, la invitación a Felipe II al bautizo de su hija recién nacida. Por último, queda por comprobar qué grado de influencia tuvieron las acciones españolas en las negociaciones secretas, solo dos años después de su elección, entre Segismundo III Vasa y el archiduque Ernesto (quien contaba con menos apoyo por parte de la nobleza que Maximiliano), con el objetivo de devolverle el reino polaco-lituano.

El análisis de los documentos muestra que la falta de empeño de medios españoles en el territorio de la República durante la tercera elección libre no excluyó acciones hacia la República polaco-lituana en otros lugares. Esto excluye la tesis de que la embajada española en Roma no se ocupaba de asuntos polaco-lituanos, 
FRENTE A LA TERCERA ELECCIÓN LIBRE EN LA REPÚBLICA POLACO-LITUANA, 1586-1589

y que los contactos entre ambos países se terminaban en Roma (Madrid-Roma; Varsovia-Roma), sin ningún enlace directo ${ }^{49}$. Como he presentado en mi análisis de fuentes, los diplomáticos de Felipe II actuaban donde tenían medios y poder, es decir en Roma. Allí buscaban aliados e intentaban establecer redes de contactos, de los que carecían en los territorios fronterizos de la Europa del Este. Este desplazamiento geográfico de las actuaciones en «el negocio de Polonia» provocó que en algunos casos, como con el duque de Saboya o con la constitución de la Santa Liga, Madrid pudiera servirse de estas actuaciones como argumento favorable en otros asuntos y otras regiones geopolíticas.

\section{Bibliografía}

Axer, J. y Fontán, A. (eds.): Españoles y polacos en la corte de Carlos V. Cartas del embajador Juan Dantisco. Madrid, 1994.

BANASZAK, M.: Z dziejów dyplomacji watykańskiej. Poselstwa obediencyjne w latach 1534-1605. Varsovia, vol. II, 1975.

BogucKa, M.: «Handel Gdańska z Półwyspem iberyjskim w I połowie XVII wieku», Przeglad Historyczny, LX, 1969, pp. 1-23.

BoguckA, M.: «Misja Franciszka Mendozy i jego opinie o Polsce», Odrodzenie i Reformacja, XIX, 1974, pp. 173-185.

BORATYŃSKi, L.: «Esteban Batory, la Hansa y la sublevación de los Paises Bajos», Boletín de la Real Academia de la Historia, 127, 1954, pp. 451-500.

BORATYŃSKI, L.: «Stefan Batory i Plan Ligi przeciw Turkom (1576-1585)», Rozprawy AU wydziat historyczno-filozoficzny, 44, 1903, pp. 197-347.

Снudoвa, B.: España y el Imperio (1519-1643). Madrid, 1963.

Colección de Documentos Inéditos para la Historia de España, t. 110 y 111, Madrid 1895. Correspondencia inédita de Don Guillén de San Clemente. Embajador en Alemania de los Reyes Don Felipe II y III sobre la intervención de España en los Sucesos de Polonia y Hungría 1581-1608, publicada por el marqués de Ayerbe, conde de San Clemente, Zaragoza 1892.

Dandelet, T. J.: La Roma Española (1500-1700). Barcelona, 2002.

Edelmayer, F.: «La red clientelar de Felipe II en el Sacro Imperio Romano Germánico», Torre de los Lujanes, 33, 1997, Madrid, pp. 129-142.

García Hernán, E.: «La Curia Romana, Felipe II y Sixto V», Hispania Sacra, vol. XLVI, 1994, pp. 640-649.

Garmendía, J. O. y Larramendi, M. L. (eds.): Índices de la correspondencia entre la Nunciatura en España y la Santa Sede, durante el reinado de Felipe II. t. I, II, Madrid 1948-1949.

49. Skowron, R.: Olivares, los Vasa y el Baltico. Polonia en la política internacional de España en los años 1621-1632. Varsovia, 2008, pp. 45-48. 
FRENTE A LA TERCERA ELECCIÓN LIBRE EN LA REPÚBLICA POLACO-LITUANA, 1586-1589

Giondano, S.: Istruzioni di Filippo III ai suoi ambasciatori a Roma 1598-1621. Roma, 2006.

Góralski, Z.: «Las relaciones históricas entre España y Polonia», Trocadero,1, 1989, pp. 37-50.

Hinojosa, R.: Los despachos de la diplomacia pontificia en España. t. I, Madrid 1896.

JanaČen, J.: Rudolf II. a jeho doba. Praga, 1987.

Kaczmarski, Z.; Leśnodorski, B.: Historia państwa i prawa Polski. t. II, Varsovia 1971.

Koller, A.: «El facción española y los nuncios en la corte de Maximiliano II y de Rodolfo II. María de Austria y la confesionalización católica del Imperio», en Martínez Millán, J. y González Cuerva, R. (eds.), La dinastía de los Austria: las relaciones entre la Monarquía Católica y el Imperio, t. I, Madrid 2011, pp. 109-124.

Levin, M. J.: Agents of empire. Spanish Ambassadors in Sixteenth-Century Italy. EUU, 2005.

MAREK, P.: «La diplomacia española y la papal en la corte imperial de Fernando II», Studia Historica. Historia Moderna, 30, 2008, pp. 109-143.

Meysztowicz, W. (ed.): Elementa ad Fontium Editiones. Roma, 1960-1992.

Nowak, A.: Was the Polish-Lithuanian Commonwealth an empire? En <http://src-h.slav. hokudai.ac.jp/coe21/publish/no7_ses/chapter12.pdf>.

PÁnek, J.: Wilhelm z Rożemberka. Polityk pojednania. Opole 2007.

Pavel, M.: «Las damas de la emperatriz María y su papel en el sistema clientelar de los Reyes españoles. El caso de María Manrique de Lara y sus hijas», en Martínez MiLlán, J., Las relaciones discretas entre las Monarquias Hispana y Portuguesa: las casas de las reinas (siglos XV-XIX), t. II, Madrid 2008, pp. 1003-1013.

Przeźdiecki, R.: «Los embajadores de España en Polonia. Desde la edad media al siglo XVII», Boletín de la Real Academia de la Historia, CXXI, 1947, pp. 397-441, además vol. CXXII, 1947 y CXXIII, 1948, pp. 295-317.

Rivero, M.: «Philip II, John III and the Sforza legacy: Patrimony and Religion in the relationships between Sweden and Spain (1573 - 1584)», en Martínez Ruiz, E. y Pazzis Pi Corrales, M. (eds.), Spain E Sweden in the Baroque Era (1600 - 1660). International Congress Records, Madrid 2000, pp. 265-277.

Rodríguez Pérez, R. A.: «Servir al rey, servir a la casa. La embajada extraordinaria del III marqués de los Vélez en el Imperio y Polonia (1572-1575)», MarTínez Millán, J. y GonzÁlez Cuerva, R. (eds.), La dinastía de los Austria: las relaciones entre la Monarquía Católica y el Imperio, t. I, Madrid, 2011, pp. 439-478.

Rodríguez-SAlgado, J. M.: "II loved him as a father loves a son... Europe damn me then, but I deserve his thanks”. Philip II’s relations with Rudolf II», en MARTíneZ Millán, J. y González Cuerva, R. (eds.), La dinastía de los Austria. Las relaciones entre la monarquía Católica y el imperio, Madrid, 2011, pp. 335-389.

Ruiz Martín, F.: Carlos V y la confederación polaco-lituana, Madrid, 1954.

Ruiz Martín, F.: «La etapa marítima de las guerras de religión. Bloqueos y contrabloqueos», Estudios de Historia Moderna, III, 1953, pp. 183-214.

Ruiz Martín, F.: «El pan de los países balticos durante las guerras de religión. Andanzas y gestiones del historiador Pedro Cornejo», Hispania, 84, 1961, pp. 549-579. 
Skoworn, R.: Olivares, los Vasa y el Báltico. Polonia en la política internacional de España en los años 1621-1632. Varsovia, 2008.

Skoworn, R.: Dyplomaci polscy w Hiszpanii w XVI i XVII wieku. Cracovia 1997.

SKoworn, R.: «Nuncjusz i ambasador. Korespondencja Annibala z Capui z Guillénem de San Clemente (1586-1591)», en DrozDowski, M. R., Walczak, W., WinszowataWalCZAK, K. (eds.), Od Kijowa de Rzymu. Z dziejów stosunków Rzeczpospolitej ze Stolica Apostolska i Ukrainq. Białystok 2012, pp. 453-467.

SKoworn, R.: «Polonia en las relaciones de los diplomáticos españoles de la segunda mitad del siglo XVI», Blanco Picado, A. I. y Eminowicz, T. (eds.), Europa del Centro y del Este y del Mundo Hispánico. Simposio Internacional de Hispanistas. Cracovia 1996, pp. 29-37.

Szelągowski, A.: Walka o Battyk 1544-1621. LVIV. 1921.

Wierzbowski, T.: «Zabiegi cesarza Maksymiliana II o koronę polską 1565 - 1576», Ateneum, III, 1879, pp. 407-446 y IV, 1879, pp. 52-89.

Wóјсıк, Z. (ed.): Historia dyplomacji polskiej. Varsovia, vol. II, 1966.

WójcIK, Z. (ed.): Polska stużba dyplomatyczna w XVI-XVII wieku. Varsovia, 1966. 